\title{
Treating surgical site infection following posterior instrumentation with free-style deepithelialized propeller flap: A case report
}

\author{
Aslı Datlı, MD'1D, İsmail Karasoy, $\mathrm{MD}^{2}$ (D), Mete Zeynal, $\mathrm{MD}^{3}$ (D) \\ ${ }^{1}$ Department of Plastic and Reconstructive Surgery, Istinye University, Medical Park Gaziosmanpaşa Hospital, Istanbul, Turkey \\ ${ }^{2}$ Department of Orthopedics and Traumatology, Gümüşhane State Hospital, Gümüşhane, Turkey \\ ${ }^{3}$ Department of Neurosurgery, Atatürk University, Faculty of Medicine, Erzurum, Turkey
}

Posterior instrumentation of the vertebral column is a surgical procedure frequently performed in both orthopedics and neurosurgery. The presence of an instrument increases the infection risk, compared to procedures without an instrument, by up to 5.6 times. ${ }^{[1]}$

Complications such as infection, implant failure, nonunion, or malunion often lead to implant removal and associated debridement, which may result in extensive posterior trunk defects. ${ }^{[2]}$

Dead space in the surgical site is a challenge for surgeons, as hematomas/seromas can accumulate in these three-dimensional wounds which can be conductive for bacterial growth. ${ }^{[3,4]}$ Therefore, dead

Received: September 04, 2020

Accepted: February 17, 2021

Published online: June 11, 2021

Correspondence: İsmail Karasoy, MD. Gümüşhane Devlet Hastanesi Ortopedi ve Travmatoloji Kliniği, 29000 Gümüşhane, Türkiye.

E-mail: ismail.karasoy@gmail.com

Doi: 10.52312/jdrs.2021.78727

Citation: Datlı A, Karasoy I, Zeynal M. Treating surgical site infection following posterior instrumentation with free-style deepithelialized propeller flap: A case report. Jt Dis Relat Surg 2021;32(2):531-535.

(02021 All right reserved by the Turkish Joint Diseases Foundation

This is an open access article under the terms of the Creative Commons Attribution-NonCommercial License, which permits use, distribution and reproduction in any medium, provided the original work is properly cited and is not used for commercial purposes (http://creativecommons.org/licenses/by-nc/4.0/).

\section{ABSTRACT}

Surgical site infection is a challenging situation for all types of surgeons. Extensive debridement with or without implant removal can create soft tissue defects. A well-vascularized, adequate soft tissue is needed to cover the wound and to fill the dead space for proper healing. Herein, we describe our approach to a large posterior trunk defect with dead space and our solution to manage an intraoperative complication using a free-style deepithelialized propeller flap.

Keywords: Microsurgery, posterior instrumentation, posterior trunk, propeller flap, surgical site infection.

space management is crucial for the successful eradication of infection in surgical site. ${ }^{[4,5]}$

Regional muscle flaps and free flaps can be used to reconstruct posterior trunk defects. However, large defects require multiple muscle flaps which may increase donor site morbidity. ${ }^{[7]}$ Also, free flaps can be challenging due to inadequate recipient vessels. Free-style propeller flaps extinguish these problems. Its free style enables a flexible design and multiple flap elevation, and its propeller nature provides sufficient bulk to obliterate dead space with minimal donor site morbidity. ${ }^{[6,7]}$

In this article, we report a case who was treated with a free-style deepithelialized propeller flap for a surgical site posterior trunk infection with a resultant dead space following implant removal and the complete debridement of the surrounding tissue.

\section{CASE REPORT}

A 68-year-old man diagnosed with a T10 burst fracture from a fall from a height underwent 


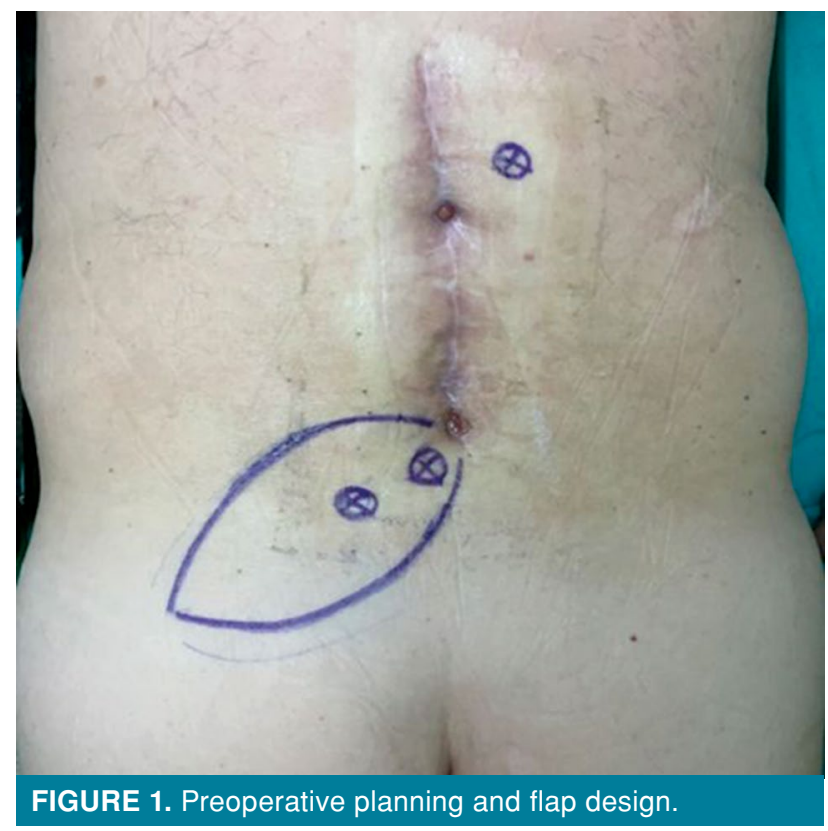

posterior instrumentation (spinous process fixation) by a neurosurgeon, and he achieved a swift recovery without complications and was discharged after one week. Six months after the operation, surgical site infection (SSI) occurred. Local debridement of the wound was done by the neurosurgeon, and oral antibiotics were initiated. However, despite this treatment, no regression was observed. The patient was hospitalized and administered intravenous antibiotic therapy. Implant failure was observed via $X$-ray at nine months. Therefore, implant removal and debridement under general anesthesia was decided due to the uncontrolled infection status. A written informed consent was obtained from the patient. The patient and/or his family were informed that data from the case would be submitted for publication and gave their consent.

Two adequate perforators, one at the caudal edge of the previous incision and another at the middle proximal part of the incision, were traced with a hand-held Doppler device prior to surgery (Figure 1). Any innominate vessel piercing throughout the fascia that has Doppler sound can be chosen as a recipient vessel. Implant removal and complete debridement of the infected tissues was conducted by the neurosurgeon (Figures 2 and 3). In order to fill the $3 \times 4 \times 5-\mathrm{cm}$ dead space resulting from the implant removal, the perforator on the caudal edge was dissected, isolated, and the flow was checked with the hand-held Doppler device. A free-style, elliptical, $8 \times 12-\mathrm{cm}$ propeller flap was designed and elevated suprafascially (Figures 4 and 5). Then, deepithelialization was initiated to bury the flap; however, during the deepithelialization process, the perforator vessels were ruptured. Re-anastomosis was unfeasible due to the complexity and scarcity of the super microsurgery and microsurgical equipment. A second propeller flap was planned from the other side of the incision. The hand-held Doppler device was, then, used to locate the two adequate perforator vessels on the other edge of the defect. Identical steps were followed during the dissection, except for deepithelialization was completed prior to elevating the flap. The deepithelialized flap was rotated 120 degrees anti-clockwise and buried into

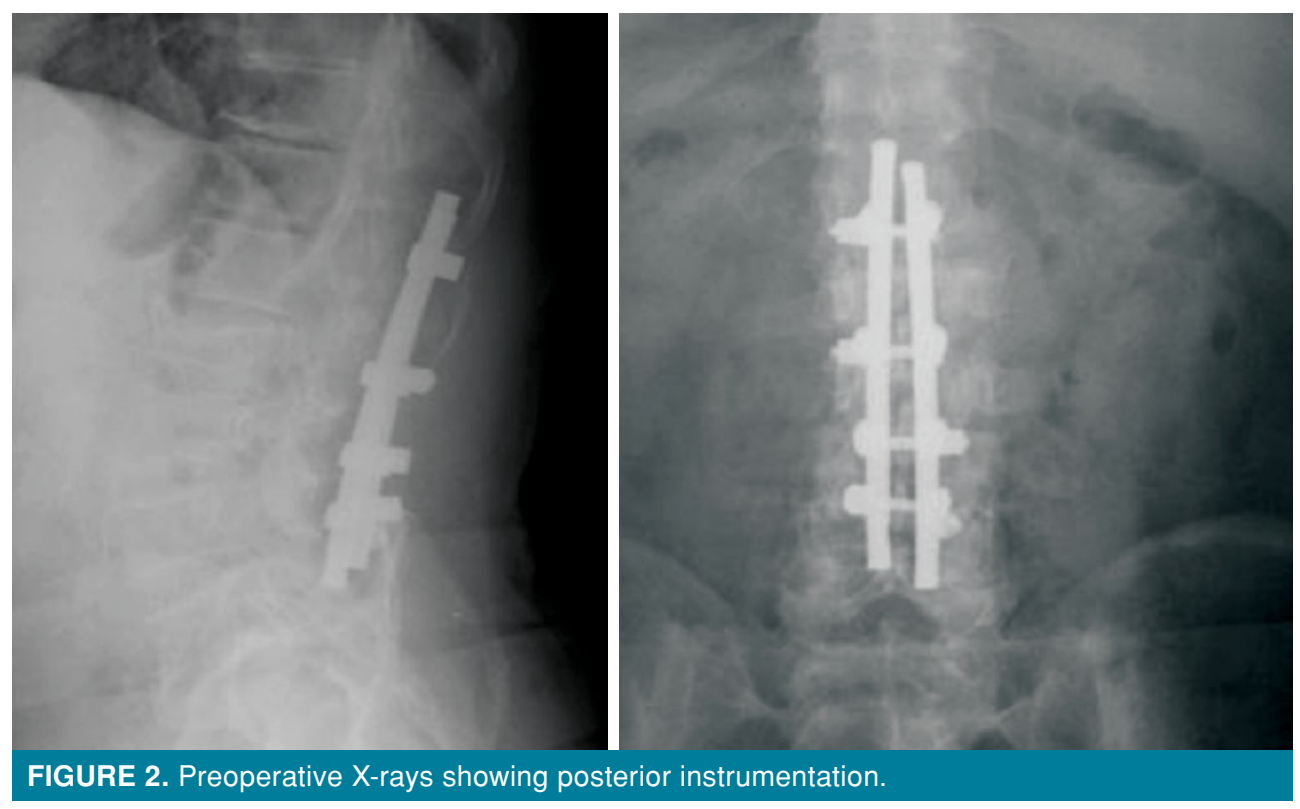




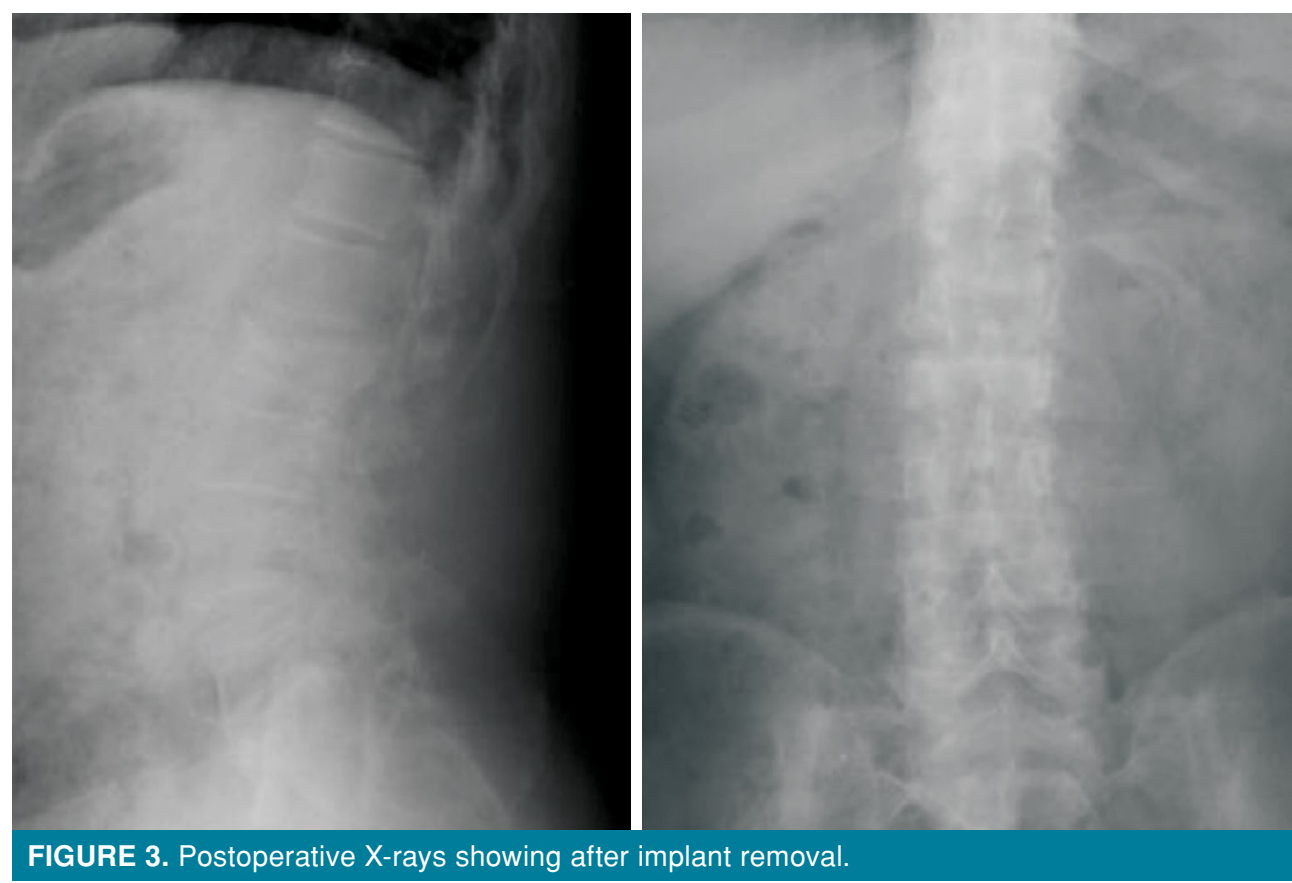

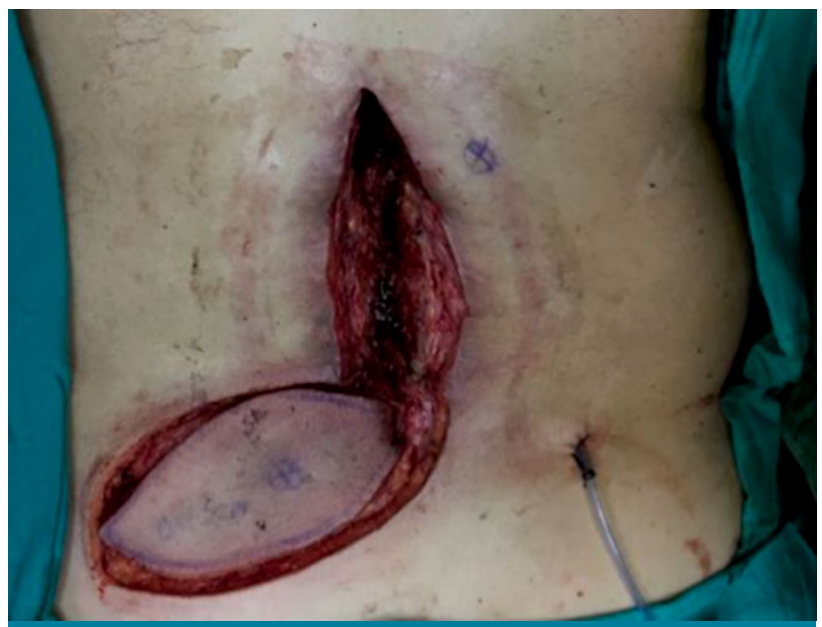

FIGURE 4. An intraoperative wound view after debridement and flap elevation.

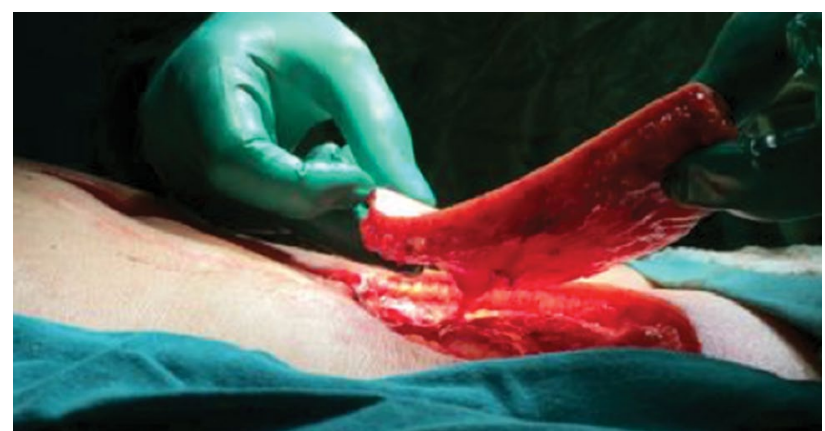

FIGURE 5. A flap view from the rear perforator vessels.

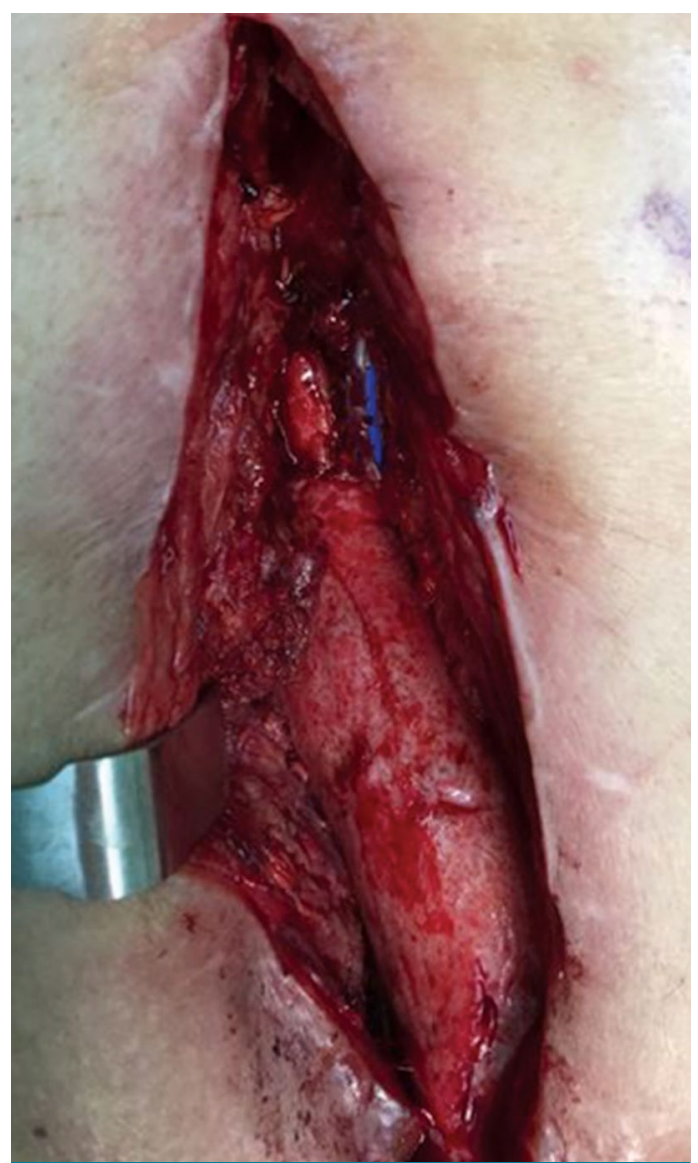

FIGURE 6. Deepithelialized flap buried into the wound. 


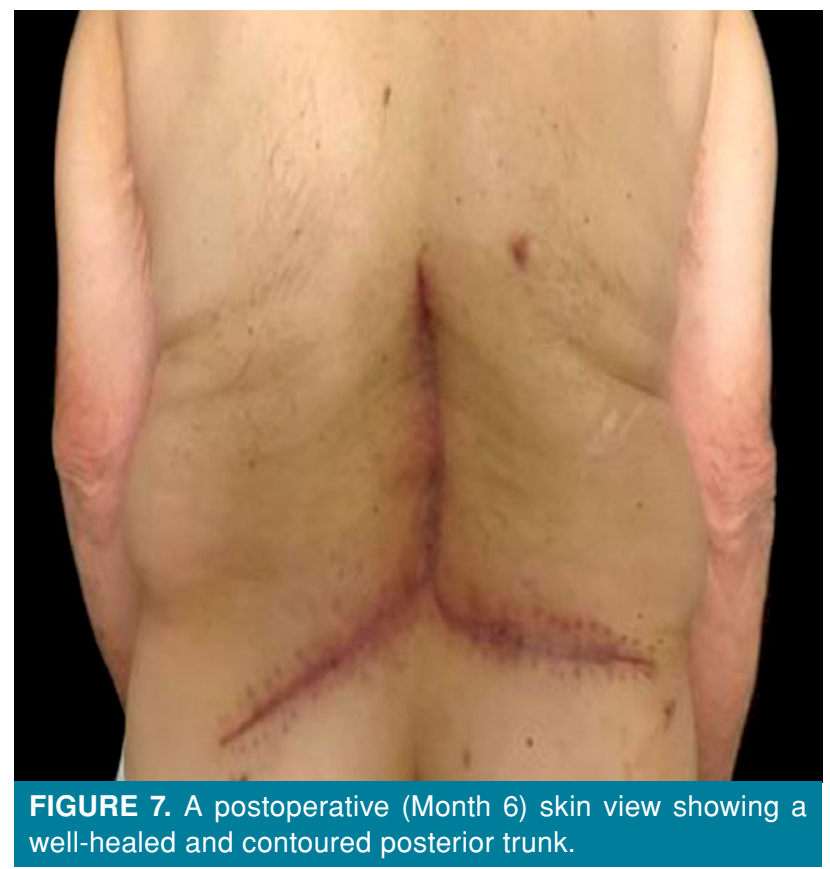

the defect (Figure 6). Following the placement of suction drains, the recipient and donor sites were closed primarily. The buried flap was monitored using the hand-held Doppler device. The patient was mobilized on Day 1, the drains were removed on Day 2, and the patient was discharged on Day 7 postoperatively. There were no complications, and the patient showed a well-healed and contoured posterior trunk at six months (Figure 7).

\section{DISCUSSION}

Posterior instrumentation is a safe and reliable procedure for many indications such as acute trauma, spinal column fracture-dislocations, scoliosis, degenerative spinal disorders, and discopathies. ${ }^{[8,9]}$ Complication rates following spine instrumentation surgery range between 1 to $7.1 \%$. ${ }^{[9,10]}$

Postoperative wound infections remain a relatively common source of morbidity and are associated with the increased cost to the patient. ${ }^{[1]}$ Furthermore, spine SSIs may increase the healthcare expenditures up to four times. ${ }^{[12]}$ Complications leading to debridement may result in implant removal and three-dimensional wounds, thereby, increasing the morbidity rates and reducing the patient's quality of life. ${ }^{[13]}$

Managing wounds with dead space, particularly following an infectious condition, still remains problematic. The amount of viable soft tissue after debridement may not be sufficient to fill the dead space and inadequate closure leads to further complications. Therefore, it is crucial to provide adequate coverage to the wound with well-vascularized tissues to obliterate any potential dead space. ${ }^{[14]}$

Free-style deepithelialized propeller flaps may be a solution for SSIs with soft tissue defects, stemming from extensive debridement and implant removal, with inadequate soft tissue, particularly following revision surgeries. ${ }^{[15]}$

The perforator flap concept was first introduced by Taylor and Palmer ${ }^{[16]}$ while the propeller flap was introduced by Hyakusoku et al. ${ }^{[17]}$ The idea of this type of flap was to utilize the existing perforator vessels surrounding the defect. Wei and Mardini ${ }^{[18]}$ introduced the free-style approach that allowed for the design of a flap based on a preoperative perforator found using the Doppler device.

Deepithelialization of the flap to reduce the dead space was first described by Hill and Riaz ${ }^{[19]}$ The free-style deepithelialized propeller flap was introduced in 2017 by Datli et al. ${ }^{[20]}$ for the treatment of three-dimensional wounds with or without skin defects, when the conventional flaps were difficult to reach or could not provide an adequate volume.

Using the perforator vessels allow this procedure to be used in most parts of the body, particularly the lower extremities, which are considered the largest donor site in the body for perforator flap harvest. ${ }^{[21]}$ The propeller design provides the ability to cover 360 degrees of the surrounding tissue, and the free-style can be used to maneuver the flap into a viable space.

Furthermore, if the defect is too large, more than one free-style propeller flap can be used. However, Maruccia et al. ${ }^{[2]}$ showed that more than one free-style propeller flap could be elevated for closing large defects in the posterior trunk. Park et al. ${ }^{[22]}$ utilized more than one free-style perforator propeller flap to close a massive posterior trunk defect and named it the jigsaw puzzle technique. This approach was utilized to treat the intraoperative complication in our case.

In conclusion, free-style deepithelialized propeller flap remains a new concept in orthoplastics. These flaps can be a solution for SSIs with soft tissue defects, stemming from extensive debridement and implant removal, with inadequate soft tissue, particularly following revision surgeries. The perforator based free-style flap can be used on any part of the body, 
where the proper vessels are found to elevate more than one flap. Performing microsurgical procedures, particularly at a local hospital setting, is a challenge for surgeons. However, this procedure is not technically demanding and gives the opportunity to address intraoperative complications in a single session.

\section{Declaration of conflicting interests}

The authors declared no conflicts of interest with respect to the authorship and/or publication of this article.

\section{Funding}

The authors received no financial support for the research and/or authorship of this article.

\section{REFERENCES}

1. Proietti L, Scaramuzzo L, Schiro' GR, Sessa S, Logroscino CA. Complications in lumbar spine surgery: A retrospective analysis. Indian J Orthop 2013;47:340-5.

2. Maruccia M, Di Taranto G, Schonauer F, D'Andrea F, Losco L, Ribuffo D, et al. Freestyle perforator puzzle flap for posterior trunk reconstruction. Ann Plast Surg 2020;85:56-60.

3. De Holl D, Rodeheaver G, Edgerton MT, Edlich RF. Potentiation of infection by suture closure of dead space. Am J Surg 1974;127:716-20.

4. Oliver RA, Lovric V, Yu Y, Christou C, Aiken SS, Cooper JJ, et al. Development of a novel model for the assessment of dead-space management in soft tissue. PLoS One 2015;10:e0136514.

5. Watt JP, Dunn RN. The Use of vacuum dressings for dead space management in deep surgical site infections allows implant and bone graft retention. Global Spine J 2017;7:756-61.

6. Oh TS, Hallock G, Hong JP. Freestyle propeller flaps to reconstruct defects of the posterior trunk: A simple approach to a difficult problem. Ann Plast Surg 2012;68:79-82.

7. Kedar DJ, Pak CJ, Suh HP, Hong JP. Propeller flaps in the posterior trunk. Semin Plast Surg 2020;34:176-83.

8. Defino HLA, Costa HRT, Nunes AA, Nogueira Barbosa M, Romero V. Open versus minimally invasive percutaneous surgery for surgical treatment of thoracolumbar spine fractures- a multicenter randomized controlled trial: study protocol. BMC Musculoskelet Disord 2019;20:397.

9. Shillingford JN, Laratta JL, Sarpong NO, Alrabaa RG, Cerpa MK, Lehman RA, et al. Instrumentation complication rates following spine surgery: A report from the Scoliosis Research Society (SRS) morbidity and mortality database. J Spine Surg 2019;5:110-5.

10. Smith JS, Shaffrey CI, Sansur CA, Berven SH, Fu KM, Broadstone PA, et al. Rates of infection after spine surgery based on 108,419 procedures: a report from the Scoliosis Research Society Morbidity and Mortality Committee. Spine (Phila Pa 1976) 2011;36:556-63.

11. Calderone RR, Garland DE, Capen DA, Oster H. Cost of medical care for postoperative spinal infections. Orthop Clin North Am 1996;27:171-82.

12. O'Neill KR, Smith JG, Abtahi AM, Archer KR, Spengler DM, McGirt MJ, et al. Reduced surgical site infections in patients undergoing posterior spinal stabilization of traumatic injuries using vancomycin powder. Spine J 2011;11:641-6.

13. Daldal I, Senkoylu A. Strategies of management of deep spinal infection: From irrigation and debridement to vacuum-assisted closure treatment. Ann Transl Med 2020;8:33.

14. Mathes DW, Thornton JF, Rohrich RJ. Management of posterior trunk defects. Plast Reconstr Surg 2006;118:73e-83e.

15. Atik OŞ. What are the expectations of an editor from a scientific article? Jt Dis Relat Surg 2020;31:597-8.

16. Taylor GI, Palmer JH. The vascular territories (angiosomes) of the body: Experimental study and clinical applications. Br J Plast Surg 1987;40:113-41.

17. Hyakusoku H, Yamamoto T, Fumiiri M. The propeller flap method. Br J Plast Surg 1991;44:53-4.

18. Wei FC, Mardini S. Free-style free flaps. Plast Reconstr Surg 2004;114:910-6.

19. Hill C, Riaz M. A new twist to the myocutaneous turnover flap for closure of a spinal defect. Plast Reconstr Surg 1998;102:1167-70.

20. Datli A, Suh H, Kim YC, Choi DH, Hong JPJ. Free-style deepithelialized propeller flaps: An ideal local flap to obliterate wounds with dead space. Plast Reconstr Surg Glob Open 2017;5:e1249.

21. AlMugaren FM, Pak CJ, Suh HP, Hong JP. Best local flaps for lower extremity reconstruction. Plast Reconstr Surg Glob Open 2020;8:e2774.

22. Park SW, Oh TS, Eom JS, Sun YC, Suh HS, Hong JP. Freestyle multiple propeller flap reconstruction (jigsaw puzzle approach) for complicated back defects. J Reconstr Microsurg 2015;31:261-7. 